\title{
New ways to sway vaccine-hesitant parents
}

\author{
Cite as: CMAJ 2017 January 23;189:E124-5. doi: 10.1503/cmaj.109-5371
}

uper heroes combatting infectious diseases are part of a burgeoning arsenal aimed at debunking pseudoscience and providing scientific evidence about vaccines to Canadians of all ages.

In a recent online Canadian survey, $19 \%$ of parents said they were vaccine hesitant, although only $3 \%$ had not vaccinated their children. Vaccine-hesitant parents typically refuse some vaccines but accept others; they may delay vaccinating and worry if they are doing the correct thing.

"Unfortunately there's a tremendous amount of misinformation about the safety and efficacy of vaccinations," said federal Minister of Health Dr. Jane Philpott in a Dec. 6 address to the Canadian Immunization Conference in Ottawa.

In the Dec. 1, 2016 Canada Communicable Disease Report almost $20 \%$ of Canadians surveyed believe vaccines are directly linked to autism (a link that was formally discredited in 2010). And according to the latest (2013) Childhood National Immunization Coverage Survey, $37 \%$ agreed with the erroneous statement that vaccines can cause the same disease they are meant to be prevent and $17 \%$ agreed with the false statement that alternative treatments can replace vaccines. Nonetheless, $97 \%$ of these parents agreed vaccines were safe, effective and important.

Some Canadians are under-immunized or unimmunized because they don't know when their vaccines are due or available, others are vaccine hesitant, and some are antivax, said Philpott. This, coupled with the "reality of microbial resistance ... threatens to undo the great strides that we've made in health interventions over the years."

The federal government is investing $\$ 25$ million over five years to improve immunization coverage. "We need to improve access to immunization across the country and meet the coverage rates that are needed for community immunity," said Philpott. "We need to figure out better how to move worried parents from no to yes. It's complex, it's sensitive, it's difficult, but ... it absolutely can be done."

\section{The vaccine hesitant}

Vaccine-hesitant parents are among the targets for initiatives from the Ottawa Hospital mHealth Research Team, led by Dr. Kumanan Wilson. It will spend $\$ 3.5$ million over three years from the Public Health Agency of Canada (PHAC) on an adverse reporting pilot, vaccine trade name catalogue, bar coding proof of concept and other projects.

The team's biggest accomplishment to date is the CANImmunize app (originally immunize(A), which was launched in 2013 and now has more than 165000 Canadian users. It tracks immunization records and provides evidence-based information about vaccines, as well as notifications of disease outbreaks and reminders when it's time to vaccinate, among other things.
Wilson says he isn't targeting antivaxers, who are unlikely to be swayed, but he's also concerned that vaccine-hesitant parents are too set in their ways to change. "By the time you're an adult a lot of belief systems are set .... They become part of your identity."

Children, he says, may be more receptive. He was surprised at the lack of literature on teaching kids about vaccines, although he did find vaccination-oriented video games and videos. He also discovered that about $90 \%$ of five- to six-yearold children have a computer or tablet.

Wilson teamed up with students from Algonquin College to develop a motion comic book, called Invasion of the Alien Zombies, a story about the body being attacked and needing to be trained to fight the invader. It launched in January on the CANimmunize app.

"Kids are all using digital technology. We should be using this," said Wilson.

\section{Social media}

Children aren't the only ones online. For adults, social media is a fertile breeding

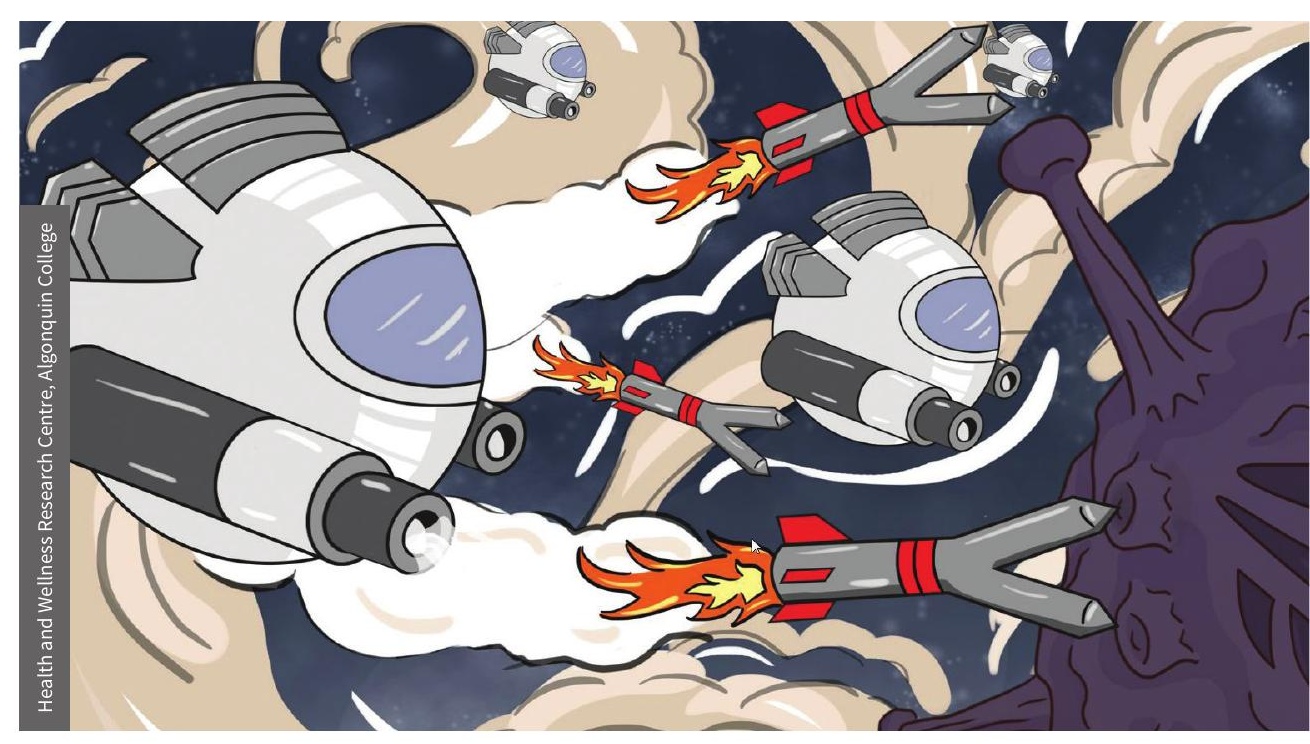

Ottawa researchers have developed a motion comic book to teach children how vaccines work. 
ground for misinformation about vaccines. "It's really where the discussion is taking place," said Patricia Salsbury, manager of the immunization promotion and education unit at the Public Health Agency of Canada. "If public health is not there as part of this narrative, then the narrative is being controlled by others."

This point was reiterated by speaker Timothy Caulfield, who holds the Canada Research Chair in Health Law and Policy at the University of Alberta. He pointed out that singer Katy Perry has 94 million followers on Twitter; the World Health Organization has three million; the Canadian Immunization Conference has 161.
"Social media is where a lot of people are getting information about vaccination," said Caulfield.

"I don't think we fight [anti-vaccine activist and actor] Jenny McCarthy with another anecdote. That's wrong. That's not scientific. But we can use story and anecdote to get across the ... good science. We need, as a community to get creative," said Caulfield.

"Call bunk when it's bunk. Step up and don't hesitate. If the scientific message isn't out there, if the truth isn't out there, the bunk wins," he said.

In addition, Caulfield said government regulators need to be more aggressive about truth in advertising, like the US Federal Trade Commission, which recently issued guidelines for homeopathy advertising. And professional regulatory colleges should fight pseudoscience with scientific standards, and more policies and statements.

"If you're a trusted voice, you can have an impact," said Caulfield.

Dr. Greg Taylor, the former chief public health officer at PHAC agreed. "One of the most important things we can do about vaccine hesitancy is to concentrate on building relationships of trust with Canadians."

Barbara Sibbald, CMAJ 